\title{
Kajian Linguistik Modern Strukturalis dalam Pembelajaran Bahasa Arab
}

\author{
Restu Budiansyah Rizki \\ Universitas Islam Negeri Maulana Malik Ibrahim Malang \\ Corresponding author: restubudiansyahrizki@gmail.com
}

\begin{abstract}
Today's modern linguistic ideas seem very hot to be discussed on the conference stages. Its presence has brought fresh air for language and education activists. Not without reason, linguistics has contributed in breaking down various aspects of linguistic material to be transformed into foreign language learning, one of which is Arabic. this has been seen with the existence of a rainbow of linguistic studies in various lines of discussion. Call it one of the most famous modern linguistic studies today is structuralism. Structuralism tries to present a language lens that suppresses aspects of behaviorism and sees that language is obtained because of a trigger factor or continuous training. The method presented in this research is entitled library research. So that the data obtained comes from theories which in their discussion address structuralist modern linguistic studies and foreign language learning. The results showed that the realm of structuralist modern linguistics is very suitable to be applied in foreign language learning, one of which is Arabic. The suitability of these applications can be echoed by the following steps, including: 1) practice repeating utterances in Arabic which can have an impact on students' habit of speaking in Arabic, 2) changing the type of sentence between isim or fi'il, 3) expansion exercises meaning in sentences with different patterns, and 4) connecting exercises.
\end{abstract}

Gagasan-gagasan linguistik modern dewasa ini tampaknya sangat hangat untuk diperbincangkan dalam panggung-panggung konferensi. Kehadirannya telah membawa angin segar bagi para pegiat bahasa maupun pendidikan. Bukan tanpa alasan, linguistik telah memberikan sumbangsihnya dalam mengurai pelbagai aspek

ISSN 2622-6146 (e) 2622-6138 (p)

(C) Alsina : Journal of Arabic Studies

http://journal.walisongo.ac.id/index.php/alsina 
materi kebahasaan untuk kemudian ditransformasikan dalam pembelajaran bahasa asing, salah satunya bahasa arab. hal tersebut telah tampak dengan adanya pelangi kajian linguistik di berbagai lini bahasan. Sebut saja salah satu pelangi kajian linguistik modern yang terkenal dewasa ini adalah strukturalisme. Strukturalisme mencoba menghadirkan kacamata bahasa yang menekan aspek behaviorisme serta memandang bahwa bahasa diperoleh sebab adanya faktor pemicu atau latihan yang bersifat kontinu. Metode yang dihadirkan dalam penelitian ini bertajuk pada penelitian pustaka. Sehingga data yang diperoleh berasal dari teori-teori yang dalam bahasannya menyapa kajian linguistik modern strukturalis dan pembelajaran bahasa asing. Hasil penelitian menunjukkan bahwa ranah kajian linguistik modern strukturalis sangat cocok untuk diaplikasikan dalam pembelajaran bahasa asing, salah satunya bahasa arab. Kecocokan aplikasi tersebut dapat digaungkan dengan adanya langkah-langkah berikut, diantaranya: 1) latihan mengulang ujaran dalam bahasa arab yang dapat berdampak pada keterbiasaan siswa dalam berucap dengan bahasa arab, 2) merubah jenis kalimat antara isim atau fi'il, 3) latihan perluasan makna dalam kalimat dengan pola berbeda, dan 4) latihan menghubungkan.

Keywords: linguistik modern; linguistik strukturalis; pembelajaran bahasa arab.

\section{Pendahuluan}

Menilik kembali perbincangan seputar bahasa, para pakar linguistik telah banyak menorehkan pemikirannya untuk sekedar mendefinisikan apa hakikat dari bahasa itu sendiri. Dalam hal ini, Ronald Wardhaugh dalam bukunya "An Introduction to Sociolinguistics" menyatakan secara singkat bahwa: "Language is what the members of particular society speak" (bahasa adalah sesuatu yang dikatakan oleh sekelompok masyarakat sosial). ${ }^{1}$ Sehingga dalam hal ini, Kridalaksana memberikan sebuah penafsiran bahwa "Bahasa adalah sistem

\footnotetext{
${ }^{1}$ Ronald Whardaugh, An Introduction To Sociolinguistics, (Black Well
} Publishing, 2010). Hlm. 1 
lambang bunyi arbitrer yang digunakan oleh para anggota kelompok sosial untuk bekerja sama, berkomunikasi, dan mengidentifikasikan diri". ${ }^{2}$

Berangkat dari definisi kridalaksana tentang bahasa, sejatinya dapat ditarik benang merah bahwa hakikat bahasa dapat dilihat dari ciri-ciri atau sifat bahasa itu sendiri yang tidak lain bahwa bahasa adalah sistem, isyarat, berupa bunyi, arbitrer, konvensional, isyarat komunikatif, bermakna. ${ }^{3}$

Apapun definisi bahasa, jika dilihat dari ciri-ciri dan sifat bahasa, pada dasarnya bahasa merupakan sistem lambang dari suatu bunyi yang digunakan oleh semua golongan masyarakat untuk suatu tujuan berinteraksi dan berkomunikasi. Bahkan dengan adanya pengakuan betapa pentingnya penggunaan bahasa untuk melakukan sebuah komunikasi, para pegiat bahasa dan hampir seluruh ahli yang bergerak dalam lini teori bahasa sekaligus praktik bahasa dalam pembelajaran menyadari bahwa dunia interaksi dan komunikasi yang dibangun dengan adanya bahasa akan berdampak lumpuh total tanpa kehadiran bahasa itu sendiri. ${ }^{4}$

Bahasa arab sebagai bagian dari rumpun bahasa semit (semitic language) menurut Ghazzawi merupakan salah satu bahasa mayor yang hampir digunakan oleh lebih dari 200 juta umat dan 20 negara untuk tujuan bertutur. Oleh karena bahasa arab digadang-gadang sebagai salah satu bahasa kitab suci dan sekaligus pedoman atau dustur (undang-undang) agama Islam di seluruh penjuru dunia, maka tidak heran jika bahasa arab adalah bahasa yang peran segnifikansi penggunaannya

2 Abdul Chaer, Linguistik Umum, (Jakarta: PT Rineka Cipta, 2007). HIm. 32.

${ }^{3}$ J. D. Parena, Kajian Linguistik Umum Historis Komparatif dan Tipologi Stryktural, (Jakarta: PT Gelora Aksara Pratama. 1991). 31.

4 Keraf, dalam: A. M. Anshor, Pengajaran Bahasa Arab: Media dan Metode-Metodenya, (Yogyakarta: Penerbit Teras, 2009), Hlm. 1. 
ditaksir paling besar di antara bahasa-bahasa yang lain, baik oleh keturunan arab ataupun bukan. ${ }^{5}$

Kemudian, pada akhir abad ke-19 atau awal abad ke-20 tepatnya tahun 1916 , lahirlah sebuah pandangan modern tentang bahasa yang dikenal dengan sebutan teori linguistik modern strukturalis. Tahun 1916 telah menjadi tahun monumental dengan adanya karya Ferdinand De Saussure yang berjudul "Course de Linguistique Generale" yang membahas pokok teori struktural sebagai pokok pemikiran linguistik modern. Di mana, sebelum munculnya teori struktural tersebut, dunia linguistik masih berkutat dengan teori linguistik tradisional. Sehingga kehadiran teori struktural telah menjadi revolusi kajian linguistik yang telah melambungkan nama Ferdinand De Saussure sebagai salah satu "Bapak Linguistik Modern".

Dengan adanya peranan penting dari suatu bahasa dan berangkat dari adanya kajian linguistik modern struktural Ferdinand De Saussure tentang linguistik inilah yang menjadi satu tonggak niatan untuk sejenak menilik kembali peranan kajian linguistik modern strukturalis dalam pembelajaran bahasa asing terutama bahasa arab bagi masyarakat non penutur bahasa arab.

\section{Frame Kajian Linguistik Modern Strukturalis}

Bilik-bilik pembahasan tentang bahasa sangat empuk untuk dikaji. Rona wajah bahasa yang beragam itulah yang menarik simpati berbagai kalangan untuk mengangkat satu tema pokok yang biasa disapa dengan istilah "linguistik". Panggung-panggung keilmuan linguistik tentang bahasa, telah memunculkan pelbagai devinisi dari bahasa itu sendiri, salah satunya Ronal Wardhaugh dalam bukunya "Introduction to Linguistis" memberikan statement dengan menganggap bahwa:

5 Azhar Arsyad, Bahasa Arab dan Metode Pengajarannya, (Yogyakarta: Pustaka Pelajar, 2004), Hlm. 1 
"Bahasa tidak lain adalah suatu sistem simbol-simbol bunyi arbitrer yang digunakan manusia untuk melakukan komunikasi". Lebih lanjut, Harimurti menguatkan devinisi tersebut dengan menganggap bahwa: "Bahasa adalah suatu sistem lambang arbitrer yang digunakan masyarakat untuk bekerja sama, berinteraksi dan mengidentifikasi sendiri".

Sementara itu, Kamus Besar Bahasa Indonesia, memberikan devinisi bahasa dalam 3 bahasan:

a. Sistem lambang bunyi berartikulasi dan bersifat arbitrer.

b. Perkataan yang dipakai suatu bangsa.

c. Percakapan atau percakapan yang baik: sopan santun, tingkah laku yang baik.

Dari definisi-definisi di atas dapat disimpulkan bahwa bahasa pada hakikatnya adalah simbol. Hubungan antar simbol inilah yang kemudian diangkat dalam kajian linguistik. ${ }^{6}$

Seperti yang sudah dijelaskan, salah satu bapak linguistik modern yang terkenal dewasa ini adalah Ferdinand De Saussure. Namanya begitu tak asing didengar oleh banyak kalangan terutama pegiat bahasa dan pengajaran bahasa. Ferdinand De Saussure merupakan ahli linguis berkebangsaan Swiss. Namanya melambung tinggi berkat pandangan-pandangannya seputar studi bahasa yang telah dimuat dalam bukunya yang berjudul "Course De Linguistique Generale" dan diterbitkan oleh beberapa murid-muridnya: "Bally dan Schehaye" sepeninggal Ferdinand. Buku tersebut bertajukkan seputar gagasangagasan mengenai bahasa yang ditulisnya semasa dalam bangku perkuliahan. Di mana, gagasan-gagasan yang membuat namanya melambung tinggi adalah seputar kajian sinkronik/diakronik dalam bahasa, perbedaan language dan pa-

${ }^{6}$ Mamluatul Hasanah, Proses Manusia Berbahasa: Prespektif AlQur'an dan Psikolinguistik, (Malang: UIN-Maliki Press, 2010), Hlm. 5., Asep Ahmad Hidayat, Filsafat Bahasa, (Bandung: PT Remaja Rosdakarya, 2006), Hlm. 22. 
role, perbedaan segnifiant dan signifie, serta hubungan sintagmatik dan paradigmatik. Yang secara sadar atau tidak sadar, keempat gagasan yang ditawarkan Ferdinand belum pernah diangkat dalam isu-isu kajian linguistik sebelumnya. ${ }^{7}$

Lebih lanjut, Dalam ranah kajian Linguistik Strukturalis, Ferdinand mencoba membahas tiga ranah bahasa yang dapat dikatakan bahwa kajian inilah yang dominan dalam pandangan Ferdinand. Ketiga ranah tersebut adalah: langage (bahasa pada umumnya yang bersifat abstrak), langue (bahasa tertentu yang bersifat abstrak), dan parole (bahasa sebagai tuturan yang bersifat kongkrit). Dalam hal ini, Ferdinand mengeluarkan celetupan bahwa kajian linguistik hanya menaruh perhatian pada langue (bahasa tertentu yang bersifat abstrak). Sedangkan parole akan lebih dominan jika dibahas dalam ranah psikologi. Sehingga ketika kedua unsur linguistik dan psikologi ingin dibahas secara lengkap, maka tak heran jika muncul istilah "psikolinguistik". Hal tersebut bukan tanpa alasan, sebab Ferdinand menganggap bahwa:

a. Langue bersifat sosial, sedangkan parole bersifat individual

b. Kedua hal ini saling bertentangan

c. Langue bersifat abstrak, sedangkan parole bersifat konkrit

d. Langue bersifat pasif, sedangkan perole bersifat aktif.

Dari keempat pandangan tersebutlah yang mengarahkan Ferdinand untuk menyimpulkan bahwa dalam ranah linguistik, yang dapat dikaji adalah langue bukan parole. ${ }^{8}$

Di samping itu, strukturalis juga menganggap bahwa bahasa dapat diperoleh dengan adanya faktor-faktor latihan yang sifatnya kontinuitas (terus-menerus). Dalam hal ini, pandangan strukturalis terhadap pemerolehan bahasa mengacu pada psikologi behaviorisme yang mengatakan bahwa segala

${ }^{7}$ Abdul Chaer, Linguistik Umum,,.. Hlm. 32.

${ }^{8}$ Abdul Chaer, Psikolinguistik: Kajian Teoritik, (Bandung: PT Rineka Cipta, 2009). HIm. 12, 66-68. 
apapun terkait kemampuan dapat terjadi dan terlaksana karena keberadaan faktor habituasi (latihan atau kebiasaan). Adapun implementasi dari kajian strukturalis adalah jika seseorang menghendaki untuk dapat memperoleh bahasa, maka tindakan yang harus ia lakukan adalah melakukannya secara terus-menerus, sebagaimana pandangan bahwa seseorang yang hidup dalam lingkungan yang menggunakan bahasa Indonesia, akan bertutur dengan bahasa Indonesia, jika orang Indonesia berada dalam lingkungan pekerjaan yang menggunakan bahasa Arab, maka ia dengan sendirinya akan memperoleh bahasa Arab sebagai alat tindak tutur. Demikianlah screenshot dari fenomena kontinuitas dalam pemerolehan bahasa. $^{9}$

Di sisi lain, pandangan Strukturalis Ferdinand menganggap bahwa bahasa merupakan sistem yang terdiri dari fonologi, morfologi, sintaksis, semantik dan leksikon. Dengan hal yang paling penting bahwa pandangan ini dapat diterapkan dalam kajian perbedaan bahasa, persamaan bahasa, dan perbandingan antar bahasa. ${ }^{10}$

Kemudian, sepanjang historisnya, kajian linguistik strukturalis diperkuat dengan munculnya ilmuan linguistik Leonard Bloomfield dari Amerika. Bloomfield merupakan salah satu penganut teori strukturalis dengan menggunakan pendekatan behaviorisme. Pandangan Bloomfield mengenai bahasa bahwa bahasa merupakan sebuah respon dari adanya stimulus yang ada di dalam tindak tutur (speech act) masyarakat. Dapat dikatakan bahwa teori linguistik akan sangat gamblang dibahasa jika kita memperhatikan kisah anekdot "Jack and Jill".

${ }^{9}$ Eko Suroso, Psikolinguistik, (Yogyakarta: Penerbit Ombak, 2016), Hlm. 50-52.

•'مرابط, تياقوت لعلاوي نجاة، أهمية اللسـانيات الملفوظية في تعليمية اللغة العربية، (جاية: جامعة عبد الرمن ميرة، 
Lebih lanjut, teori linguistik strukturalis Bloomfield berpendapat bahwa bahasa merupakan sebuah kumpulan ujaran yang muncul dalam suatu masyarakat. Ujaran-ujaran inilah yang dengan teori distribusi Bloomfield dapat dikaji dari datadata potongan sebuah tuturan yang disusun secara liniar. Sehingga muncullah beberapa istilah dalam term Bloomfield yang layak diketahui, diantaranya:

a. Fonem, adalah satuan bunyi terkecil dalam leksikon dan distingtif suatu bahasa seperti bunyi u pada kata indonesia "bakul" karena bunyi "u" merupakan distingtif bunyi "a" dari kata "bakal" yang keduanya memiliki makna yang berbeda.

b. Morfem, satuan terkecil unit bahasa yang memiliki makna. Seperti kata "me- dalam kata menerima, yang memiliki makna.

c. Frase, unit bahasa yang setidaknya terdiri dari dua bentuk seperti kata "adik saya"

d. Kata, sebuah unit bahasa yang terdiri dari satu bentuk bebas dan satu bentuk tidak bebas seperti kata "pukul+an".

e. Kalimat, sebuah ujaran lengkap.

Dalam hal ini, Bloomfield berusaha memenggal-menggal bagian-bagian bahasa tersebut ke dalam hakikat keterhubungan yang kemudian dikenal dengan istilah "distribusi". 11

Berangkat dari beberapa term di atas, aliran strukturalis menurut hemat penulis adalah mengkaji suatu bahasa sesuai hierarkial sebagaimana terlihat dalam gambar 1 .

Sehingga, dalam garis besarnya, teori linguistik modern strukturalis memandang bahwa konsep bahasa adalah:

a. Bahasa merupakan tanda (signifiant dan signifie) yang bersifat arbitrer dan konvensional.

${ }^{11}$ Abdul Chaer, Psikolinguistik: Kajian Teoritik, (Bandung: PT Rineka Cipta, 2009). HIm. 69-72. 
Kajian Linguistik Modern Strukturalis dalam Pembelajaran Bahasa Arab

b. Bahasa merupakan sistem ujaran.

c. Bahasa merupakan kebiasaan (sistem habituasi)

d. Berbahasa merupakan proses stimulus-respon (S-R).

e. Gramatika bahasa ditentukan faktor keumuman.

Sebagai tambahan, dalam bukunya yang lain, disebutkan:

a. Level-level gramatika disusun secara rapi dari beberapa unsur fonem, morfem, kata, frasa, dan kalimat atau dalam hirarkial disebut sebagai kajian fonologi, morfologi, sintaksis dan semantik.

b. Tekanan analisis pada bidang morfologi.

c. Bahasa merupakan deretan sintagmatik dan paradigmatik.

d. Analisis bahasa secara deskriptif, dan

e. Analisis struktur bahasa berdasarkan unsur langsung. ${ }^{12}$

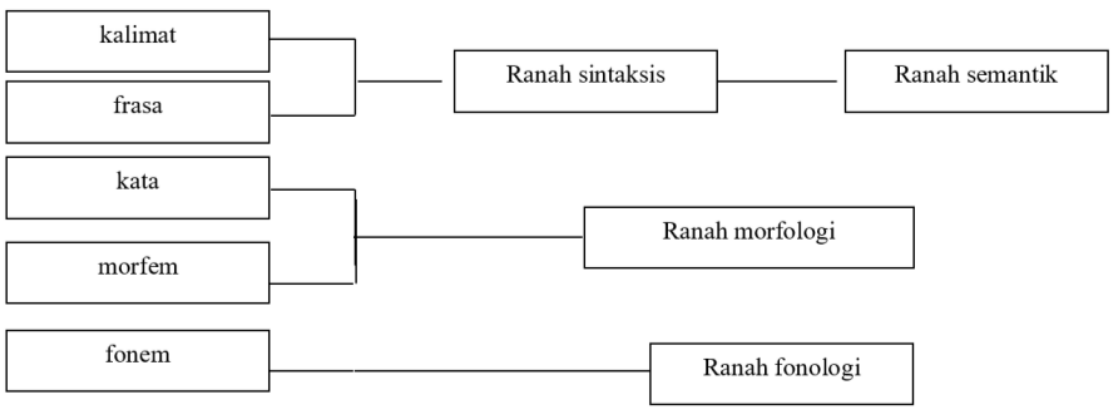

Gambar 1

\section{Urgensi Kajian Linguistik Modern Strukturalis Dalam Pembelajaran Bahasa Arab}

Sebelum menginjak lebih jauh terkait aplikasi linguistik modern strukturalis dalam pembelajaran bahasa arab, secara

${ }^{12}$ Soeparno, Aliran Tagmemik: Teori: Analisis, dan Penerapannya Dalam Pembelajaran Bahasa, (Yogyakarta: Tiara Wacana, 2008), HIm. 89., lihat juga dalam bukunya, Dasar-Dasar Linguistik Umum, (Yogyakarta: Tiara Wacana Yogya, 2002), Hlm. 50-52. 
umum pembelajaran bahasa dapat dilakukan dengan beberapa metode, diantaranya:

a. Metode induktif

Metode induktif ada sebuah metode yang digunakan untuk mengurai dari hal-hal yang khusus terlebih dahulu untuk kemudian dilakukan generalisasi. Jika di sandarkan pada pebelajaran bahasa arab, maka tidak menutup kemungkinan untuk menjabarkan beberapa contoh terkait bahasa arab, kemudian diambilkan sebuah kaidah bahasa.

b. Metode deduktif

Metode deduktif merupakan salah satu kebalikan dari metode induktif. Dimana frame metode tersebut bermula dengan sesuatu hal yang umum umum untuk kemudian diparsialkan kepada bentuk khusus. Jika disandarkan pada pembelajaran bahasa arab, maka tidak menutup kemungkinan untuk diambilkan kaidah bahasa, kemudian dijabarkan dalam bentuk contoh terkait bahasa arab. ${ }^{13}$

Kemudian, berdasarkan pada beberapa pandangan teori linguistik modern strukturalis terhadap suatu bahasa yang mengcover bahwa bahasa adalah sistem tanda yang bersifat arbitrer dan konvensional, bahasa merupakan suatu ujaran, bahasa merupakan hasil dari faktor kebiasaan (habituasi), proses berbahasa merupakan manifestasi S-R (Stimulus-Respon), dan gramatika bahasa ditentukan oleh faktor keumuman, maka dengan pandangan tersebut, Lado mencanangkan 17 buah butir prinsip-prinsip dalam pembelajaran bahasa dengan berangkat dari pandangan teori linguistik modern strukturalis terhadap suatu bahasa, diantaranya adalah:

a. Prinsip ujaran mendahului tulisan, sebab tulisan dalam hal bahasa merupakan suatu manifestasi dari adanya ujaran.

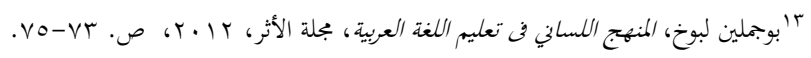


b. Prinsip kalimat sederhana sebagai dasar percakapan, karena memang dalam pembelajaran bahasa harus mengedepankan kebertahapan.

c. Prinsip pemantapan pola sehingga menjadi sebuah kebiasaan, seperti: penggunaan pola $\mathrm{S}+\mathrm{P}+(\mathrm{O})$ (Subjek+Predikat+(Objek)) ataupun sebaliknya $\mathrm{P}+\mathrm{S}+(\mathrm{O})$ (Predikat+Subjek+(Objek).

d. Prinsip penggunaan sistem suara, yaitu dengan mengedapankan ujaran.

e. Prinsip pengembangan dan pengontrolan vokabuler (kosa kata).

f. Prinsip pengetengahan problem.

g. Prinsip tulisan merupakan manifestasi dari ujaran, sehingga penggunaan pembelajaran berupa suara lisan lebih didahulukan sebelum akhirnya menyentuh ranah tulisan.

h. Prinsip penyajian pola secara bertahap, yaitu dengan dimulai dari pola $\mathrm{S}+\mathrm{P}$, Kemudian beralih menjadi $\mathrm{S}+\mathrm{P}+\mathrm{O}$, Dan akhirnya $\mathrm{S}+\mathrm{P}+\mathrm{O}+\mathrm{K}$ ataupun sebaliknya tergantung penggunaan kata dalam kalimat.

i. Prinsip menghindari bahasa terjemah. Tanpa menterjemahkan bahasa tujuan ke dalam bahasa ibu.

j. Prinsip penggunaan standar bahasa yang otentik tanpa menggunakan bahasa yang tidak standar dalam penggunaannya.

k. Prinsip belajar berbahasa melalui praktik

l. Prinsip membentuk respon dalam tidak berbahasa, yaitu dengan menghasilkan sebuah respon dari stimulus yang dirangsang.

m. Prinsip kenormalan kecepatan serta gaya bahasa.

n. Prinsip penekanan kembali.

o. Prinsip arah budaya bahasa sasaran.

p. Prinsip jandungan isi bahasa, dan

q. Prinsip kebermanfaatan belajar bahasa. 
Di mana, dengan berdasar pada prinsip-prinsip tersebut serta dengan adanya sekian banyak metode atau teknik pembelajaran bahasa arab, pada hakikatnya pembelajaran bahasa yang bertolak dari teori linguistik modern strukturalis ini telah menumbuh-kembangkan keterampilan berbahasa melalui salah satu teknik drill atau praktek. ${ }^{14}$

Prinsip-Prinsip yang digagas linguistik modern strukturalis dan pembelajaran bahasa Arab itulah yang menjadi patokan atau jawaban atas pertanyaan "mengapa linguistik strukturalis sangat urgen dalam pembelajaran bahasa Arab".

\section{Aplikasi Linguistik Modern Strukturalis Dalam Pem- belajaran Bahasa Arab}

Berangkat dari beberapa point penting dalam kajian linguistik modern strukturalis yang digagas Lado dalam prinsipprinsip pembelajaran bahasa miliknya, Maka, ada beberapa hal yang dapat dilakukan dalam pembelajaran bahasa arab dengan pendekatan linguistik strukturalis diantaranya:

a. Latihan mengulang-ulang ujaran dalam bahasa arab. Dilakukan agar siswa terbiasa dalam mengucapkan bahasa arab.

b. Latihan merubah jenis kalimat (fi'il/isim). Dilakukan agar siswa tidak sebatas memahami satu bentuk kalimat saja dalam bahasa Arab.

c. Latihan perluasan makna dalam kalimat. Dilakukan agar pemahaman siswa tidak terbatasi dengan pola kalimat S+P saja, melainkan lebih luas.

d. Latihan menghubungkan. Dilakukan agar siswa mampu bermain kohesi dan koherensi sebuah kalimat. ${ }^{15}$

${ }^{14}$ Soeparno, Aliran Tagmemik: Teori: Analisis, dan Penerapannya Dalam Pembelajaran Bahasa, (Yogyakarta: Tiara Wacana, 2008), Hlm. 89.90.

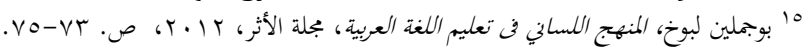


Kajian Linguistik Modern Strukturalis dalam Pembelajaran Bahasa Arab

Sehingga, pembelajaran bahasa arab dengan pendekatan strukturalis dapat dilakukan dengan beberapa langkah berikut ini:

Dalam hal ini, penulis mencoba menggunakan metode deduktif dalam pembelajaran bahasa.

a. Menuliskan kaidah bahasa arab sebagai patokan

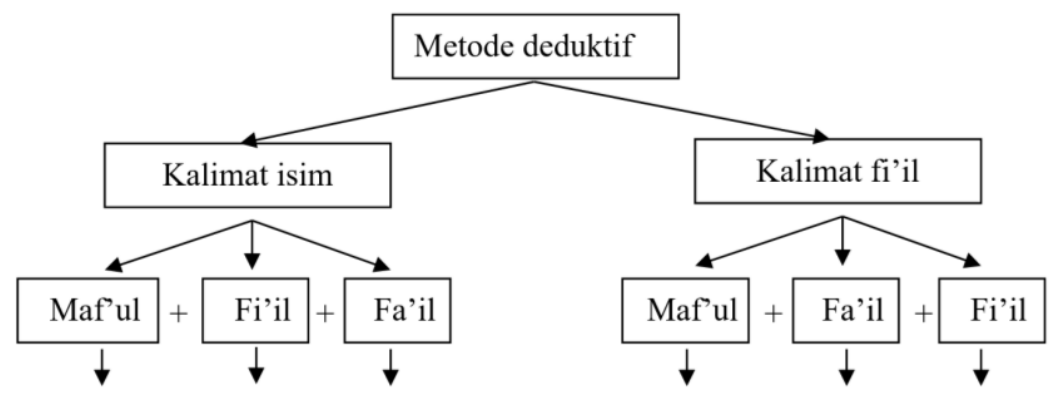

b. Memberikan contoh sesuai kaidah bahasa arab

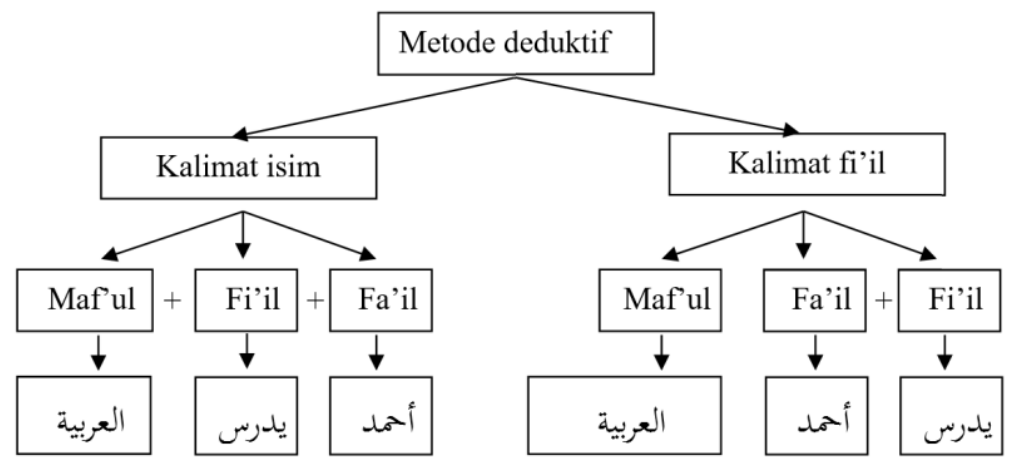

c. Mengaplikasikan dalam beberapa keterampilan berbahasa

Dalam hal ini, dapat dilakukan sesuai dengan beberapa point di atas, yaitu:

* Latihan mengulang-ulang ujaran dalam bahasa arab. Dilakukan agar siswa terbiasa dalam mengucapkan bahasa arab 
Restu Budiansyah Rizki

\begin{tabular}{cc}
\hline Murid & Guru \\
\hline اللغة العربية & اللغة العربية \\
\hline
\end{tabular}

* Latihan merubah jenis kalimat (fi'il/isim). Dilakukan agar siswa tidak sebatas memahami satu bentuk kalimat saja dalam bahasa Arab.

يعلم المدرس الطلاب في الفصل ========> جملة فعلية (kalimat fi'il) المدرس يعلم الطلاب في الفصل ========> جملة اسمية (kalimat isim)

* Latihan perluasan makna dalam kalimat. Dilakukan agar pemahaman siswa tidak terbatasi dengan pola kalimat $\mathrm{P}+$ $\mathrm{S}$ (kalimat fi'il) atau $\mathrm{S}+\mathrm{P}$ (kalimat isim) saja, melainkan lebih luas yakni $\mathrm{P}+\mathrm{S}+\mathrm{O}+\mathrm{K}$ atau $\mathrm{S}+\mathrm{P}+\mathrm{O}+\mathrm{K}$

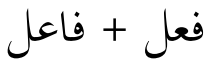

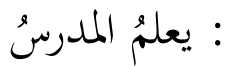

$$
\begin{aligned}
& \text { فعل + فاعل + مفعول به } \\
& \text { : يعلُ الملدردُ الطلابَ } \\
& \text { فعل + فاعل + مفعول به } 1 \text { + مفعول به } \\
& \text { : يعلَّ الملدرسٌ الطلابَ اللغةَّ العربيةً } \\
& \text { فعل + فاعل + مغعول به } 1 \text { + مفعول به ب + البيان } \\
& \text { : يعلُ الملدرسُ الطلابَ اللغةَ العربيةَ في الفصل }
\end{aligned}
$$

\section{Kesimpulan}

Dalam ranah kajian Linguistik Strukturalis, Ferdinand mencoba membahas tiga ranah bahasa yang dapat dikatakan 
bahwa kajian inilah yang dominan dalam pandangan Ferdinand. Ketiga ranah tersebut adalah: langage (bahasa pada umumnya yang bersifat abstrak), langue (bahasa tertentu yang bersifat abstrak), dan parole (bahasa sebagai tuturan yang bersifat kongkrit). Dalam hal ini, Ferdinand mengeluarkan celetupan bahwa kajian linguistik hanya menaruh perhatian pada langue (bahasa tertentu yang bersifat abstrak). Sedangkan parole akan lebih dominan jika dibahas dalam ranah psikologi. Sehingga ketika kedua unsur linguistik dan psikologi ingin dibahas secara lengkap, maka tak heran jika muncul istilah "psikolinguistik".

Pembelajaran bahasa dapat dilakukan dengan beberapa metode, diantaranya: Metode induktif adalah sebuah metode yang digunakan untuk mengurai dari hal-hal yang khusus terlebih dahulu untuk kemudian dilakukan generalisasi. Metode deduktif merupakan salah satu kebalikan dari metode induktif. Dimana frame metode tersebut bermula dengan sesuatu hal yang umum umum untuk kemudian diparsialkan kepada bentuk khusus

Aplikasi Linguistik Modern Strukturalis Dalam Pembelajaran Bahasa Arab adalah dengan cara: Latihan mengulangulang ujaran dalam bahasa arab. Dilakukan agar siswa terbiasa dalam mengucapkan bahasa arab, Latihan merubah jenis kalimat (fi'il/isim). Dilakukan agar siswa tidak sebatas memahami satu bentuk kalimat saja dalam bahasa Arab. Dan Latihan perluasan makna dalam kalimat. Dilakukan agar pemahaman siswa tidak terbatasi dengan pola kalimat $\mathrm{S}+\mathrm{P}$ saja, melainkan lebih luas.

\section{Referensi}

Abdul Chaer, Linguistik Umum, (Jakarta: PT Rineka Cipta, 2007)

Abdul Chaer, Psikolinguistik: Kajian Teoritik, (Bandung: PT Rineka Cipta, 2009) 
Restu Budiansyah Rizki

Asep Ahmad Hidayat, Filsafat Bahasa, (Bandung: PT Remaja Rosdakarya, 2006)

Azhar Arsyad, Bahasa Arab dan Metode Pengajarannya, (Yogyakarta: Pustaka Pelajar, 2004)

Eko Suroso, Psikolinguistik, (Yogyakarta: Penerbit Ombak, 2016)

J. D. Parena, Kajian Linguistik Umum Historis Komparatif dan Tipologi Stryktural, (Jakarta: PT Gelora Aksara Pratama. 1991)

Keraf, dalam: A. M. Anshor, Pengajaran Bahasa Arab: Media dan Metode-Metodenya, (Yogyakarta: Penerbit Teras, 2009)

Mamluatul Hasanah, Proses Manusia Berbahasa: Prespektif AlQur'an dan Psikolinguistik, (Malang: UIN-Maliki Press, 2010)

Ronald Whardaugh, An Introduction To Sociolinguistics, (BlackWell Publishing, 2010)

Soeparno, Aliran Tagmemik: Teori: Analisis, dan Penerapannya Dalam Pembelajaran Bahasa, (Yogyakarta: Tiara Wacana, 2008)

Soeparno, Aliran Tagmemik: Teori: Analisis, dan Penerapannya Dalam Pembelajaran Bahasa, (Yogyakarta: Tiara Wacana, 2008)

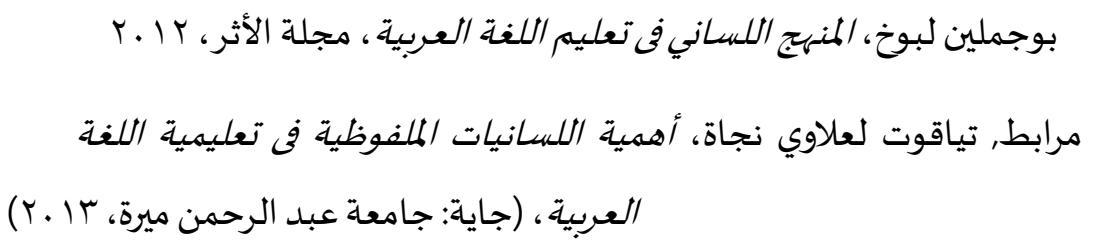

